\title{
Targeted disruption of the iNOS gene improves adipose tissue inflammation and fibrosis in leptin-deficient $o b / o b$ mice: role of tenascin C
}

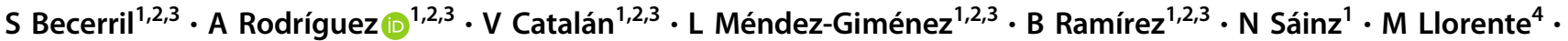 \\ $X$ Unamuno $^{1,4} \cdot \mathrm{J}$ Gómez-Ambrosi (iD ${ }^{1,2,3} \cdot \mathrm{G}$ Frühbeck $^{1,2,3,5}$
}

Received: 6 July 2017 / Revised: 12 December 2017 / Accepted: 21 December 2017 / Published online: 15 February 2018

(c) The Author(s) 2018. This article is published with open access

\begin{abstract}
Background/Objectives: Obesity is related to a dynamic extracellular matrix (ECM) remodeling, which involves the synthesis and degradation of different proteins, such as tenascin C (TNC) in the adipose tissue (AT). Given the functional relationship between leptin and inducible nitric oxide synthase (iNOS), our aim was to analyze the impact of the absence of the $i N O S$ gene in AT inflammation and ECM remodeling in $o b / o b$ mice.

Subjects/Methods: The expression of genes involved in inflammation and ECM remodeling was evaluated in 10-week-old male double knockout (DBKO) mice simultaneously lacking the $o b$ and $i N O S$ genes as well as in $o b / o b$ mice classified into three groups [control, leptin-treated $\left(1 \mathrm{mg} \mathrm{kg}^{-1} \mathrm{day}^{-1}\right)$ and pair-fed].

Results: Leptin deficiency increased inflammation and fibrosis in AT. As expected, leptin treatment improved the obesity phenotype. iNOS deficiency in ob/ob mice improved insulin sensitivity, AT inflammation, and ECM remodeling, as evidenced by lower AT macrophage infiltration and collagen deposition, a downregulation of proinflammatory and profibrogenic genes Tnf, Emrl, Hifla, Col6al, Col6a3, and Tnc, as well as lower circulating TNC levels. Interestingly, leptin upregulated TNC expression and release in 3T3-L1 adipocytes, and iNOS knockdown in 3T3-L1 fat cells produced a significant decrease in basal and leptin-induced Tnc expression.

Conclusions: Ablation of $i N O S$ in leptin-deficient mice improved AT inflammation and ECM remodeling-related genes, attenuating fibrosis, and metabolic dysfunction. The activation of iNOS by leptin is necessary for the synthesis and secretion of TNC in adipocytes, suggesting an important role of this alarmin in the development of AT inflammation and fibrosis.
\end{abstract}

\section{Introduction}

Obesity constitutes a chronic low-grade inflammatory condition, leading to robust morphological and functional changes within adipose tissue (AT), including the

Electronic supplementary material The online version of this article (https://doi.org/10.1038/s41366-018-0005-5) contains supplementary material, which is available to authorized users.

\footnotetext{
G Frühbeck

gfruhbeck@unav.es

1 Metabolic Research Laboratory, Clínica Universidad de Navarra, Pamplona, Spain

2 CIBER Fisiopatología de la Obesidad y Nutrición, Instituto de Salud Carlos III, Madrid, Spain
}

accumulation of immune cells, the dynamic remodeling of the extracellular matrix (ECM), and the altered production of adipokines, among others ${ }^{1,2}$. An increased macrophage recruitment into AT and their polarization towards a proinflammatory M1 phenotype represents a hallmark of obesity-associated inflammation ${ }^{3-6}$. M1 macrophages constitute the principal source of many of the circulating proinflammatory factors and cytokines, such as tumor necrosis factor alpha $(\mathrm{TNF}-\alpha)$ or interleukin $6(\mathrm{IL}-6)^{5,7}$.

3 Obesity and Adipobiology Group, Instituto de Investigación Sanitaria de Navarra (IdiSNA), Pamplona, Spain

4 Medical Engineering Laboratory, University of Navarra, Pamplona, Spain

5 Department of Endocrinology \& Nutrition, Clínica Universidad de Navarra, Pamplona, Spain 
These inflammatory markers have direct effects on cellular metabolism, leading to decreased AT expandability, development of fibrosis, and dysfunction ${ }^{8-11}$. Similar to other inflammatory processes, white AT (WAT) inflammation is intrinsically linked to oxidative stress. The high amount of nitric oxide (NO) synthesized by inducible NO synthase (iNOS) acts with reactive oxidative species producing nitrosative stress, playing a key role in the impairment of adipocyte function and glucose tolerance ${ }^{12,13}$.

In the context of obesity, the AT ECM undergoes considerable pathological and dynamic remodeling associated with fibrotic deposition, infiltration of proinflammatory macrophages, and increased angiogenesis ${ }^{14,15}$. The excessive accumulation of ECM components (tenascins, collagens, or fibrin, among others) damages AT homeostasis and reduces tissue plasticity leading to adipocyte dysfunction, ectopic lipid deposition in peripheral tissues, tissue inflammation, and metabolic disorders ${ }^{15,16}$. One important feature of AT expansion and the subsequent accumulation of ECM components is AT hypoxia, which ultimately leads to fibrosis ${ }^{17}$. Tenascin $\mathrm{C}$ (TNC), which belongs to the damage-associated molecular patterns family, constitutes a large hexameric glycoprotein highly expressed where tissue structures are dramatically remodeled, including embryonic development, cancer invasion, or wound healing ${ }^{18}$. TNC is associated with tissue injury as well as inflammation and modulates fibrotic and inflammatory responses in diverse diseases, such as liver fibrosis, arthritis, or obesity by inducing the production of proinflammatory cytokines $^{19-21}$. Our group has recently described that TNC participates in the etiopathology of obesity via AT inflammation ${ }^{22}$.

Obesity is typically associated with high levels of leptin, the product of the $o b$ gene predominantly expressed in adipocytes $^{23}$. In addition to its physiological role in the regulation of food intake and energy expenditure, leptin is an important element of the innate and adaptive immune system that mediates an inflammatory response by regulating the production of proinflammatory cytokines, including TNF- $\alpha$, IL- 1 , and IL- $6{ }^{24}$. These cytokines also regulate leptin expression, sustaining a chronic proinflammatory state ${ }^{25}$. Since many biological functions of leptin are induced via $\mathrm{NO}^{26-31}$, our aim was to evaluate the effects of the disruption of the iNOS gene in wild type and $o b / o b$ mice on AT inflammation and fibrosis ${ }^{26,32}$. To further confirm the potential participation of NO, the effect of the pharmacological inhibition of iNOS with $N_{\omega}$-nitro-L-arginine methyl ester hydrochloride (L-NAME), a non-selective NOS inhibitor, and L- $N^{6}-$ (1-iminoethyl)-lysine (L-NIL), a selective iNOS inhibitor, as well as the effect of $i N O S$ gene silencing on the leptin-induced production of proinflammatory factors was analyzed in murine 3T3-L1 adipocytes.

\section{Material and methods}

\section{Generation of double knockout mice lacking the ob and iNOS genes}

Male $o b / o b$ mice were intercrossed with female iNOS knockout mice $\left(\mathrm{iNOS}^{--}\right)$) on a C57BL/6J background (Jackson Laboratories, Bar Harbor, ME, USA) in order to generate a double knockout (DBKO) mouse simultaneously lacking the $o b$ and the $i N O S$ genes, as previously detailed ${ }^{26}$. Male mice were weaned at 21 days of age and genotyped. Animals had free access to tap water and were fed ad libitum with a normal chow diet $(12.1 \mathrm{~kJ}$ : $4 \%$ fat, $82 \%$ carbohydrate, and $14 \%$ protein, Diet 2014S; Teklad Global Diets, Harlan, Barcelona, Spain). Leptin-deficient $o b / o b$ mice were classified into three groups: control, leptin-treated $\left(1 \mathrm{mg} \mathrm{kg}^{-1}\right.$ day ${ }^{-1}$ ) and pair-fed ( $n=5$ per group) in a blind, randomized study, as previously described ${ }^{33}$. The control and pair-fed groups were injected with vehicle (phosphate-buffered saline), while the leptin-treated group was intraperitoneally administered with leptin (Bachem, Bubendorf, Switzerland) twice a day at 08:00 and 20:00 for 28 days. Control and leptin-treated groups were fed ad libitum with a rodent maintenance diet, while the daily food intake of the pair-fed group was matched to the amount eaten by the leptin-treated group the day before in order to discriminate the inhibitory effect of leptin on appetite. In order to study the effect of iNOS deletion in a model of diet-induced obesity, 4-week-old male C57BL/6J wild type $(n=8)$ and $i \mathrm{NOS}^{-/-}$mice $(n=8)$ were fed for 8 weeks with a high-fat diet (HFD) $(23 \mathrm{~kJ} / \mathrm{g}$ : $60 \%$ fat, $26 \%$ carbohydrate, and $14 \%$ protein; F3282, BioServ, Frenchtown, NJ, USA). All animals were maintained at room temperature (RT) on a 12:12 light-dark cycle (lights on at 08:00 a.m.) with a relative humidity of $50 \pm 10 \%$ and under pathogen-free conditions. Body weight and food intake were registered twice weekly. Twelve-week-old mice were sacrificed by $\mathrm{CO}_{2}$ inhalation under fasting conditions. Cardiac puncture was used for blood collection, and sera samples were obtained by cold centrifugation $\left(4^{\circ} \mathrm{C}\right)$ at $700 \mathrm{~g}$ for $15 \mathrm{~min}$ and stored at $-20^{\circ} \mathrm{C}$. Epididymal fat depots (EWAT) were carefully excised, weighed, frozen in liquid nitrogen, and stored at $-80^{\circ} \mathrm{C}$. Biopsies of EWAT were also fixed in $4 \%$ formaldehyde for immunohistochemical analyses. All experimental procedures conformed to the European Guidelines for the Care and Use of Laboratory Animals (Directive 2010/63/EU) and the study was approved by the Ethical Committee for Animal Experimentation of the University of Navarra (042/03 and 041/08).

\section{Blood measurements}

Blood glucose was measured using an automatic glucose sensor (Ascensia Elite, Bayer, Barcelona, Spain). Serum 
concentrations of triglycerides, free fatty acids (Wako Chemicals, GmbH, Neuss, Germany), and glycerol (Sigma, St. Louis, MO, USA) were measured by enzymatic methods using commercially available kits as previously described. Insulin and adiponectin were determined by enzyme-linked immunosorbent assay (ELISA) (Crystal Chem, Inc., Chicago, IL, USA and BioVendor Laboratory Medicine, Inc., Modrice, Czech Republic, respectively) as previously described ${ }^{34}$. Intra- and inter-assay coefficients of variation for measurements of insulin and adiponectin were 3.5 and $6.3 \%$, respectively, for the former, and 5.6 and $7.2 \%$, for the latter. The homeostatic model assessment (HOMA) was calculated as an indirect measure of insulin resistance with the formula: fasting insulin $\left(\mu \mathrm{U} \mathrm{mL}^{-1}\right) \times$ fasting glucose $\left(\mathrm{mmol} \mathrm{L}^{-1} 22.5^{-1}\right)$. Circulating levels of TNC were determined by ELISA (IBL International $\mathrm{GmbH}$, Hamburg, Germany). Intra- and inter-assay coefficients of variation for measurements of TNC were $3.5 \%$ and $6.3 \%$, respectively ${ }^{26,35}$.

\section{RNA extraction and real-time PCR}

Total RNA was isolated from EWAT samples and 3T3-L1 adipocytes using the QIAzol ${ }^{\circledR}$ Reagent (Invitrogen, Barcelona, Spain) and purified with the RNeasy Lipid Tissue kit (Qiagen) for AT or RNeasy Micro kit (Qiagen) for adipocytes, according to the manufacturer's instructions. Samples were treated with DNase I (RNase-free DNase Set; Qiagen). For first-strand cDNA synthesis, constant amounts of $2 \mu \mathrm{g}$ of total RNA isolated from EWAT and adipocyte cultures were reverse-transcribed as described earlier ${ }^{36}$. Specific primers and probes to each target gene were designed using the software Primer Express 2.0 (Applied Biosystems, Foster City, CA, USA) (Suplemental Table 1). The cDNA was amplified using the TaqMan ${ }^{\circledR}$ Universal PCR Master Mix (Applied Biosystems) and the transcript levels for egf-like module-containing mucin-like hormone receptor-like 1 or F4/80 (Emrl), tumor necrosis factor $\alpha$ (Tnf), hypoxia-inducible factor 1, $\alpha$ subunit (Hifa), collagen type VI alpha 1 and 3 chains (Col6al and Col6a3, respectively), fatty acid synthase (Fasn), vascular endothelial growth factor A (Vegfa), PR domain containing 16 (Prdm16), uncoupling protein 1 (Ucp1), cell death inducing DFFA-like effector c (Cidec), peroxisome proliferatoractivated receptor-gamma (Pparg), and tenascin C (Tnc) were quantified by Real-Time PCR (7300 Real-Time PCR System; Applied Biosystems). All results were normalized to the levels of $18 S$ rRNA (Applied Biosystems) and relative quantification was calculated using the $\Delta \Delta \mathrm{Ct}$ formula ${ }^{37}$. Relative mRNA expression was expressed as fold expression over the calibrator sample. All samples were run in triplicate and the average values were calculated.

\section{Western blot studies}

Tissues were homogenized and protein content was measured as previously described ${ }^{26}$. Blots were incubated overnight at $4{ }^{\circ} \mathrm{C}$ with murine monoclonal anti-TNC (MA516086; ThermoFisher Scientific Inc., Rockford, USA) at $1: 10,000$ or murine monoclonal anti- $\beta$-actin (A5441; Sigma) at 1:5000. The antigen-antibodies complexes were visualized using peroxidase-conjugated antirabbit or anti-mouse $\operatorname{IgG}$ antibodies (1:10,000 and 1:5000, respectively) and the enhanced chemiluminescence ECL detection system (Amersham Biosciences, Buckinghamshire, UK). The intensity of the bands was determined by densitometric analysis with the Gel Doc ${ }^{T M}$ gel documentation system and Quantity One 4.5.0 software (Bio-Rad) and normalized with $\beta$-actin densitometric values. All assays were performed in duplicate.

\section{Histological studies}

The immunodetection of TNC and F4/80 in sections of EWAT $(6 \mu \mathrm{m})$ was carried out using an indirect immunoperoxidase method, as previously described ${ }^{26}$. Sections were incubated overnight at $4{ }^{\circ} \mathrm{C}$ with rabbit polyclonal anti-TNC (NB11068136; Novus Biologicals, Abingdon, UK) or rat polyclonal anti-F4/80 (ab100790; Abcam Ltd., Cambridge, UK) antibodies both diluted 1:100 in TBS $\left(0.05 \mathrm{~mol} \mathrm{~L}^{-1}\right.$ Tris-HCl buffer, $0.5 \mathrm{~mol} \mathrm{~L}^{-1} \mathrm{NaCl}, \mathrm{pH}$ 7.36). After three washes (5 min each) with TBS, sections were incubated with Dako Real ${ }^{\mathrm{TM}}$ EnVision $^{\mathrm{TM}}$ HRP-conjugated anti-rabbit/ mouse (Dako, Glostrup, Denmark) or HRP-conjugated antirat IgG diluted in TBS (1:200) for $1 \mathrm{~h}$ at RT. After washing in TBS, the immunocomplexes were visualized by adding $0.5 \mathrm{mg} \mathrm{mL}^{-1} \quad 3$,3-diaminobenzidine (DAB)/0.03\% $\mathrm{H}_{2} \mathrm{O}_{2}$ solution (Dako) as a developing system, and Harris hematoxylin solution (Sigma) as counterstaining. Sections were dehydrated, coverslipped, and observed under a Zeiss Axiovert 40 CFL optic microscope (Zeiss, Göttingen, Germany). Negative control slides without primary antibody were included for the assessment of nonspecific staining.

The quantification of $\mathrm{F} 4 / 80^{+}$cells and crown-like structures (CLS) in EWAT ( $n=5$ per group) were analyzed using a double-blind protocol. Images of five fields were captured at magnification of $\times 200$ and the percentage of $\mathrm{F} 4 / 80^{+}$cells ( $\mathrm{F} 4 / 80^{+}$cells/total number of cells) as well as CLS, defined as a circular region surrounded by F4/80+ cells, were counted using the AxioVision 4.6.3 image analysis software (Zeiss).

Fat cell size was evaluated by analyzing the crosssectional area (CSA) of adipocytes in EWAT. Briefly, sections $(6 \mathrm{~mm})$ of $4 \%$ formaldehyde-fixed and paraffinembedded EWAT biopsies were stained with hematoxylin-eosin. Images of five fields per section from 
each animal were captured with a $\times 200$ magnification, and the adipocyte CSA from, at least, 100 cells/section were measured using AxioVision Release 4.6.3 software (Zeiss).

\section{Quantification and characterization of fibrotic depots}

Sections of formalin-fixed paraffin-embedded EWAT (6 $\mu \mathrm{m})$ were dewaxed with xylene, hydrated with decreasing concentrations of ethanol, and stained with $1 \%$ Sirius red (Sigma) to visualize collagen fibers. Images of five fields per section from each animal ( $n=3 /$ per group) were obtained at $\times 200$ magnification and the fibrous tissue area stained with Sirius red/total amount of tissue was measured using the Image $\mathbf{J}$ software, as described previously ${ }^{38}$.

\section{Cell cultures}

Murine 3T3-L1 fibroblasts (ATCC ${ }^{\circledR}$ CL-173 ${ }^{\mathrm{TM}}$ ) were differentiated into adipocytes, as previously described ${ }^{39}$. 3T3-L1 cells were seeded at $2 \times 10^{5}$ cells/well and grown in adipocyte medium [DMEM/F-12 [1:1] (Invitrogen, Paisley, UK), 16 $\mu \mathrm{mol} \mathrm{L}{ }^{-1}$ biotin, $18 \mu \mathrm{mol} \mathrm{L}^{-1}$ panthotenate, $100 \mu \mathrm{mol} \mathrm{L}^{-1}$ ascorbate and antibiotic-antimycotic] supplemented with $10 \%$ newborn calf serum (NCS) . After 4 days, the medium was switched to adipocyte medium supplemented with $3 \%$ NCS, $0.5 \mathrm{mmol} \mathrm{L}^{-1}$ 3-isobutyl-1-methylxanthine (IBMX), $0.1 \mu \mathrm{mol}$ $\mathrm{L}^{-1}$ dexamethasone, and $10 \mu \mathrm{gL}^{-1}$ insulin. After a 3-day induction period, cells were fed every 2 days with the same medium but without IBMX supplementation for the remaining 7 days of adipocyte differentiation.

In a first set of experiments, differentiated 3T3-L1 adipocytes were serum-starved for $24 \mathrm{~h}$ and quiescent cells were stimulated with recombinant murine leptin $(10 \mathrm{nmol} \mathrm{L}$ ${ }^{-1}$ ) (450-31; PeproTech EC, Inc., Rocky Hill, NJ, USA) or tenascin C $\left(10 \mathrm{nmol} \mathrm{L}^{-1}\right)$ (3358-TC-050; R\&D Systems, Minneapolis, MN, USA) for $24 \mathrm{~h}$. In a second set of experiments, leptin $\left(10 \mathrm{nmol} \mathrm{L}^{-1}\right)$-treated 3T3-L1 adipocytes were incubated in the presence of the PI3K inhibitor wortmannin (Tocris, Ellisville, MO, USA) $\left(10 \mu \mathrm{mol} \mathrm{L}^{-1}\right)$, L-NAME, a nonspecific NOS inhibitor (N5751, Sigma) or L-NIL, selective inhibitor of iNOS (I8021; Sigma) (all 10 $\mu \mathrm{mol} \mathrm{L}{ }^{-1}$ ) for $24 \mathrm{~h}$. The concentrations of leptin, tenascin C, and pharmacological inhibitors to perform the experiments were chosen on the basis of previous studies carried out in our laboratory ${ }^{29}$. One sample per experiment was used to obtain control responses in the presence of the solvent.

\section{iNOS knockdown in 3T3-L1 adipocytes by small interfering RNA}

For gene silencing studies, small interfering RNA (siRNA) targeting mouse iNOS and specific scramble negative control siRNA were used. Briefly, differentiated 3T3-L1 adipocytes (day 7 of differentiation) were transfected with scramble or two pairs of iNOS siRNAs $\left(200 \mathrm{pmol} \mathrm{L}^{-1}\right.$ siRNA $/ 2 \times 10^{5}$ cells per well) (ID18126 Trilencer-27 Mouse siRNA; Origene, Herford, Germany and ID156549 Mouse siRNA; ThermoFisher Scientific, Waltham, USA) diluted in Opti-MEM (Invitrogen) and mixed with Lipofectamine $^{\mathrm{TM}} 2000$ transfection reagent for $4 \mathrm{~h}$ at $37^{\circ} \mathrm{C}$, according to the manufacturer's instructions. The treatment with the two specific iNOS siRNA resulted in $45 \%$ and $36 \%$ average knockdown of mRNA of $i N O S$, respectively (Supplemental Fig. 1), leading to the selection of iNOS siRNA ID18126 for the iNOS knocking down studies. iNOS-silenced 3T3-L1 adipocytes were serum-starved for $24 \mathrm{~h}$ and then treated with recombinant murine leptin $(10$ $\mathrm{nmol} \mathrm{L}{ }^{-1}$ ) for $24 \mathrm{~h}$.

\section{Statistical analysis}

Data are expressed as the mean \pm SEM. The PS Power and Sample Size Calculations software (edition 3.0.43; Vanderbilt Biostatistics, Nashville, TN, USA) was used to determine the power of the study and sample size calculation. Differences between groups were assessed by a twoway ANOVA. In case of interaction between factors (lack of the $i N O S$ or $o b$ genes), a one-way ANOVA followed by Tukey's or LSD post hoc tests were applied. Moreover, comparisons between $o b / o b$ groups and controls were analyzed by one-way ANOVA followed by Tukey's post hoc tests. Statistics were calculated by the SPSS 15.0 software (SPSS, Inc., Chicago, IL, USA). A $p$-value less than 0.05 was considered statistically significant.

\section{Results}

\section{iNOS deficiency improved metabolic profile and AT function in ob/ob mice}

Metabolic characteristics of wild type and $o b / o b$ mice lacking the $i N O S$ gene are shown in Supplemental Table 2. In agreement with our previous studies ${ }^{26}, i N O S$ disruption in $o b / o b$ mice caused a reduction in body weight as well as an improvement in glucose and lipid metabolism as compared to $o b / o b$ counterparts. Although a large controversy exists on the role of iNOS on glucose homeostasis, ${ }^{40-42}$ our results are in agreement with our previous studies ${ }^{26}$. In order to analyze the impact of the absence of $i N O S$ on AT in ob/ob mice, markers of adipogenesis (Pparg, Fasn, and Cidec) and fat browning (Prdm16 and Ucpl) were evaluated. As shown in Fig. 1a and Supplemental Fig. 2A, ob/ $o b$ mice exhibited larger adipocytes with the deletion of the $i N O S$ gene in $o b / o b$ mice dramatically decreasing $(p<$ 
Fig. $1 \mathrm{iNOS}^{-1-}$ mice are protected against adipose tissue inflammation and fibrosis induced by high-fat diet (HFD)induced obesity and leptin deficiency. a Representative images (magnification $\times 100$, scale bar $=50 \mu \mathrm{m})$ of the specific macrophage marker F4/ 80 and $\mathbf{b}$ CLS in EWAT of the experimental animals. c

Representative Sirius red

staining (magnification $\times 200$,

scale bar $=50 \mu \mathrm{m})$ and $\mathbf{d}$ fibrous tissue area in EWAT ( $n=4-5$ per group). Wild-type (WT) fibrosis area in white adipose tissue (WAT) was assumed to be 100. One-way ANOVA

followed by post hoc Tukey's test was used for comparisons of quantitative variables. $* p<0.05$ ${ }^{* *} p<0.01$ vs WT mice; ${ }^{\# \# p} p<$ 0.01 vs $o b / o b$ mice.
A
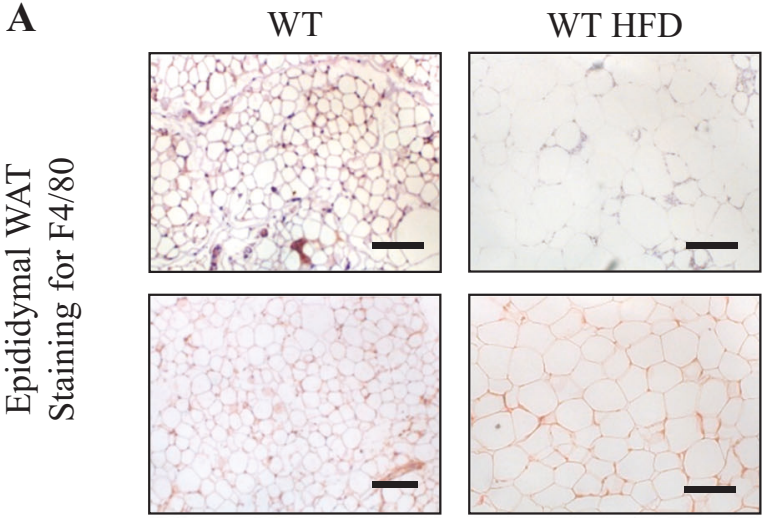

$i N O S^{-1}$

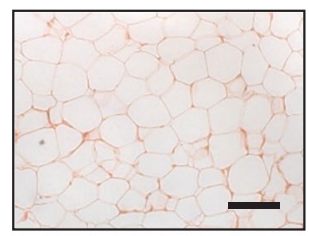

$i N O S^{-/} \mathrm{HFD}$
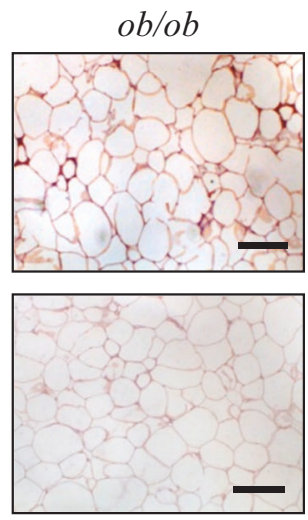

DBKO

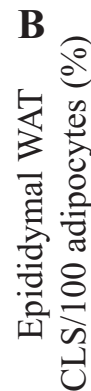

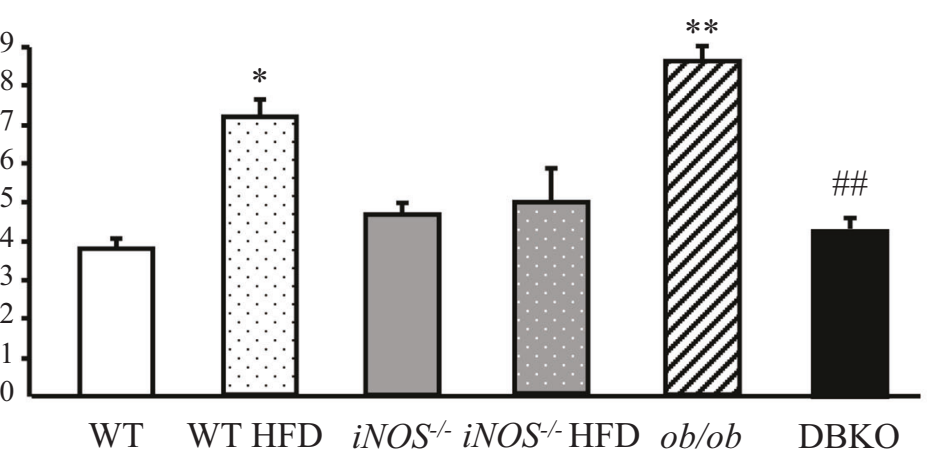

C
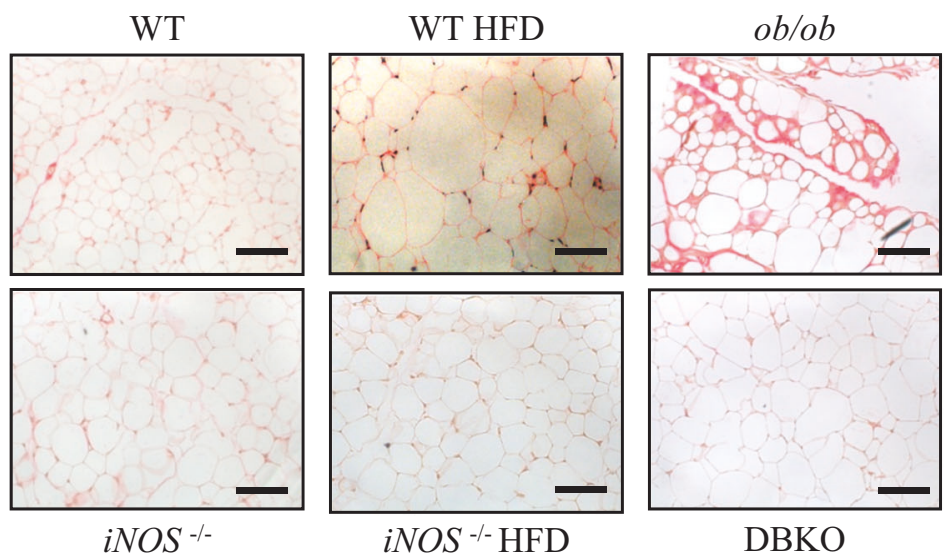

$i_{N O S}{ }^{-/} \mathrm{HFD}$

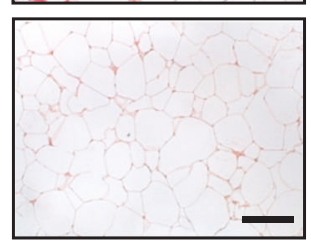

DBKO

D

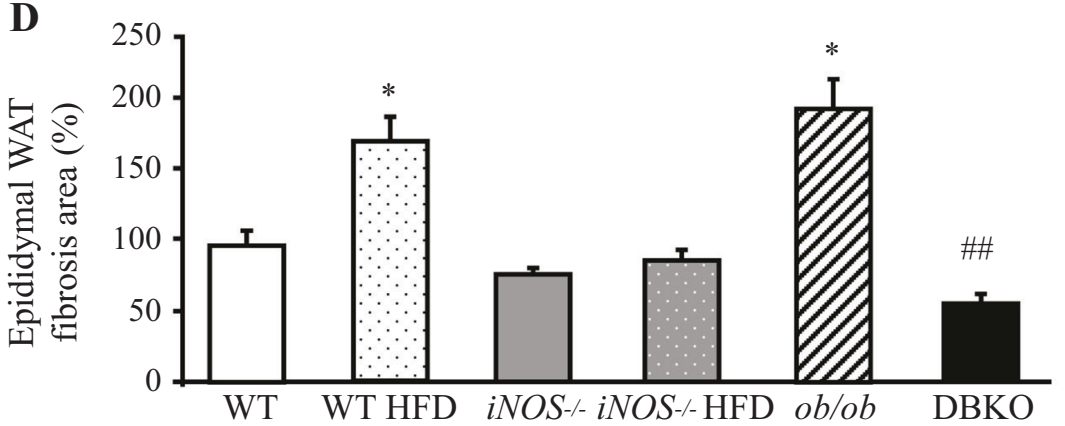


0.001) adipocyte size in epididymal AT. In line with this observation, a tendency towards an increase in Pparg (Supplemental Fig. 2B) as well as an upregulation of Fasn (Supplemental Fig. 2C) was observed in epididymal AT of $o b / o b$ mice. The deletion of $i N O S$ significantly decreased Fasn mRNA levels, but not Pparg transcripts. Leptin deficiency was also related to an upregulation of Cidec and a downregulation of Prdm16 and Ucpl in subcutaneous AT (SCWAT) (Supplemental Figs. 2D, 2E and 2F). Interestingly, the deletion of iNOS significantly $(p<0.05)$ increased Prdm16 mRNA expression levels and tended to increase Ucpl transcripts, without changes in Cidec transcripts. Taken together, iNOS deletion improved AT function in $o b / o b$ mice.

\section{iNOS deficiency decreased AT inflammation and ECM remodeling in ob/ob mice}

The histological staining of F4/80, a macrophage-specific cell surface marker, revealed an increased AT inflammation in $o b / o b$ mice as evidenced by higher $\mathrm{F} 4 / 80^{+}$cells as well as CLS, whereas DBKO mice showed significantly less macrophage infiltration in the EWAT (Fig. 1a, b). The protective effects of the lack of the iNOS gene on AT inflammation were also confirmed in a model of dietinduced obesity, which was associated with an increased number of CLS, while iNOS KO mice fed a HFD exhibited a decrease in CLS (Fig. 1a, b). Since our study was mainly focused on the functional relationship between leptin and iNOS in the onset of AT inflammation and fibrosis, the subsequent experiments were set in the context of leptin deficiency. Consistent with the previous observations, leptin deficiency was associated with increased mRNA levels of genes involved in the proinflammatory response, such as the macrophage selective marker Emrl, Tnf, and Hifla in EWAT (Fig. 2a-c). DBKO mice simultaneously lacking $o b$ and $i N O S$ genes displayed a significant decrease in Emrl, Tnf, and Hifla transcripts in EWAT compared to ob/ob mice (Fig. 2a-c). Interestingly, transcript levels of Vegfa, a member of the VEGF family involved in angiogenesis in response to AT hypoxia, were markedly decreased in leptindeficient mice (Fig. 2d), which is in accordance with previous reports ${ }^{38,43,44}$. Moreover, iNOS deficiency further decreased Vegfa mRNA in EWAT of wild type and $o b / o b$ mice (Fig. 2d), suggesting that iNOS plays a crucial role in AT hypoxia To get wider knowledge of the impact of leptin and $i N O S$ deficiency on AT inflammation, the expression and tissue distribution of the alarmin TNC was also evaluated in EWAT. Leptin-deficient $o b / o b$ mice exhibited a four-fold increase in Tnc mRNA levels compared to wildtype mice (Fig. 2e) as well as a marked TNC immunostaining in histological sections of EWAT in the mature adipocytes and, to a higher extent, in the stroma-vascular fraction cells (Fig. 2f). Accordingly, serum TNC levels were significantly increased $(p<0.05)$ in $o b / o b$ mice. iNOS disruption in $o b / o b$ mice was translated into a downregulation of Tnc transcript levels in EWAT as well as in circulating levels of this alarmin (Fig. 2e, g).

We next investigated whether leptin and $i N O S$ deficiency influenced AT fibrosis. Analysis of Sirius red-stained sections revealed a dramatic increase in the amount of fibrosis in leptin-deficient mice compared to wild-type mice, whereas $i N O S^{-/-}$mice exhibited significantly less fibrotic changes in EWAT (Fig. 1c, d). Moreover, iNOS deficiency also improved the increase in the amount of AT fibrosis in mice fed a HFD (Fig. 1c, d). Fibrosis amount, distribution, and collagen types I, III, and VI exhibit different characteristics not only in the context of obesity but also as regards fat depot localization ${ }^{45}$. Thus, we analyzed the impact of $i N O S$ deficiency on the expression of the collagen type VI subtypes Col6al and Col6a3 in epididymal and subcutaneous AT fibrosis of our experimental animals. The mRNA levels of collagen type VI (Col6al and Col6a3) were increased in both EWAT and SCWAT of leptindeficient mice, with $i N O S$ disruption reducing Col6al, but not Col6a3, transcript levels (Fig. 3a-d), suggesting that the iNOS pathway is partly responsible for the increased collagen production.

\section{Leptin replacement partially reduced the inflammation and fibrosis in adipose tissue of $o b / o b$ mice}

The ponderal and biochemical characteristics of wild type and $o b / o b$ mice are described in Supplemental Table 3. Leptin administration reversed the obese and diabetic phenotype of $o b / o b$ mice, corroborating previous findings of our group ${ }^{33}$. Leptin administration, as well as pair-feeding of $o b / o b$ mice, prevented the increased mRNA expression of Emr, Tnf, Hifla, Col6al, Col6a3, and Tnc in the EWAT of $o b / o b$ mice (Fig. 4a-e), supporting the idea that the inflammatory response and extracellular matrix remodeling are common phenomena of the obese state. Serum TNC levels were also normalized after leptin administration (Fig. 4f).

\section{Leptin treatment increased proinflammatory genes in differentiated 3T3-L1 adipocytes}

To gain further insight into the role of leptin on the inflammation and fibrosis in WAT, we next examined the expression of inflammatory and fibrotic genes in undifferentiated 3T3-L1 preadipocytes and differentiated 3T3-L1 adipocytes. Because leptin treatment did not modify the transcript levels of the representative studied genes involved in inflammation and fibrosis Emr, Tnf, Hifla, Col6al, 
A

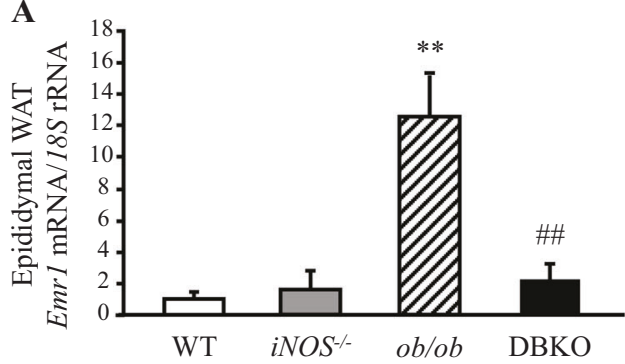

C

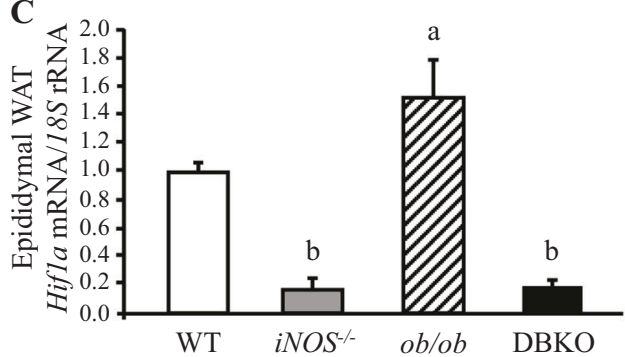

$\mathbf{E}$

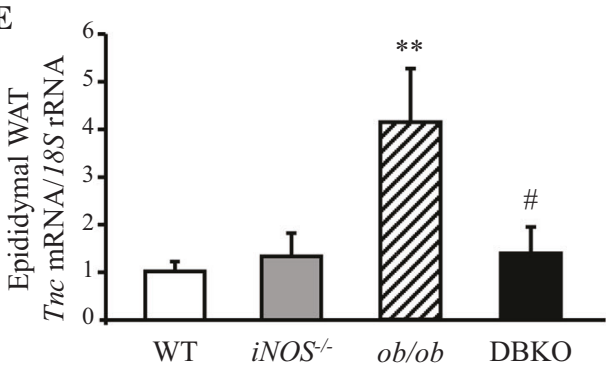

G

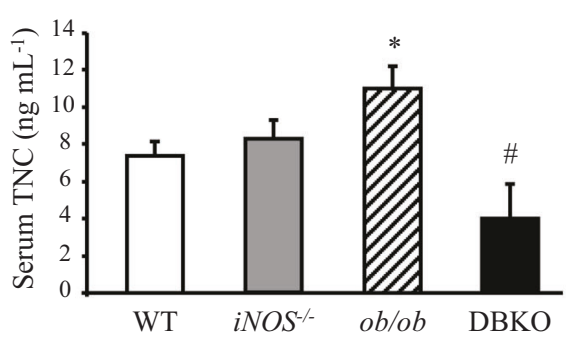

Fig. 2 iNOS deficiency improves the expression of factors involved in adipose tissue inflammation and hypoxia in the context of leptin deficiency. Gene expression levels of proinflammatory markers Emrl (a), $\operatorname{Tnf}(\mathbf{b})$, and $\operatorname{Tnc}(\mathbf{e})$ as well as hypoxia markers Hifla (c) and $V e g f a(\mathbf{d})$ genes in EWAT $(n=5)$. The gene expression in WT mice was assumed to be 1 . f Immunohistochemistry of TNC in EWAT of wild type (WT) and $o b / o b$ mice (magnification $\times 400$, scale bar $=50$

Col6a3, and Tnc in undifferentiated 3T3-L1 preadipocytes (Supplemental Fig. 3), we focused next on differentiated 3T3-L1 adipocytes. Leptin stimulation significantly increased Tnf expression levels in differentiated 3T3-L1 adipocytes, without changes in mRNA levels of Hifla or Col6a3 (Fig. 5a-c). As expected, the expression of Emrl was no detected in differentiated adipocytes (data not shown). The exposure of differentiated 3T3-L1 adipocytes to physiological concentrations $\left(10 \mathrm{nmol} \mathrm{L}^{-1}\right)$ of leptin for $24 \mathrm{~h}$ showed a tendency towards an increased Tnc gene
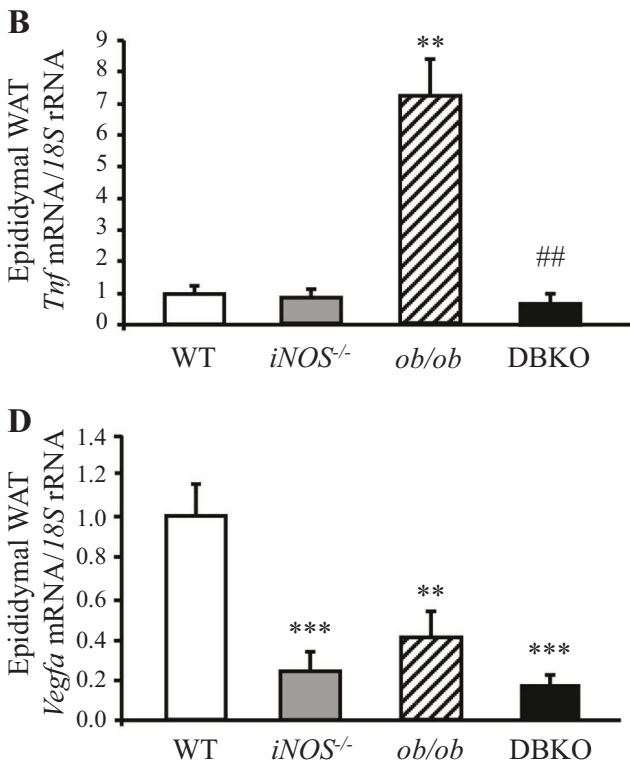

$\mathbf{F}$

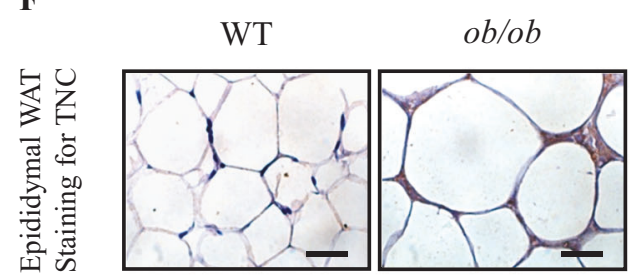

$\mu \mathrm{m})$. $\mathrm{g}$ Serum TNC levels of the different experimental groups ( $n=5$ per group). Differences between groups were analyzed by two-way ANOVA or one-way ANOVA followed by Tukey's post hoc test when an interaction between factors was detected. ${ }^{a} p<0.05$, effect of the absence of $o b$ gene, ${ }^{\mathrm{b}} p<0.01$ effect of the absence of the $i N O S$ gene. $* p<0.05, * * p<0.01, * * * p<0.001$ vs WT mice; ${ }^{\#} p<0.05,{ }^{\# \#} p<$ 0.01 vs $o b / o b$ mice

expression $(p=0.06) \quad$ (Fig. 5d) with a significantly increased release $(p<0.05)$ of TNC (Fig. 5e). Nevertheless, treatment of 3T3-L1 adipocytes with TNC did not change the transcription of Tnf or fibrotic genes, including Col6al and Col6a3 (Fig. 5f-h). Due to the fact that the phosphatidylinositol-3-kinase (PI3K) signaling pathway mediates several biological actions of leptin ${ }^{46}$, the effect of preincubating 3T3-L1 adipocytes with the PI3K inhibitor wortmannin before the addition of leptin was determined in a second subset of experiments. A significant decrease $(p<$ 

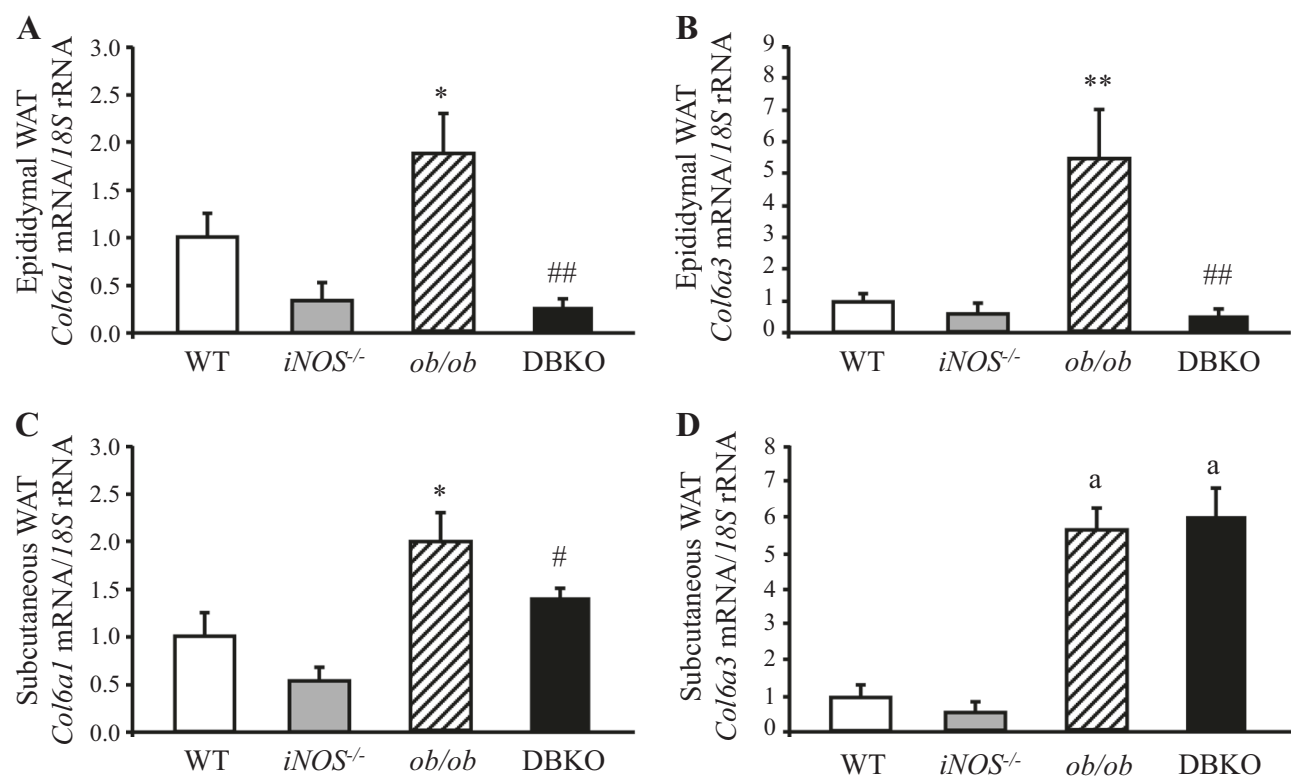

Fig. 3 Lack of $i N O S$ reduced the increase in collagen VI expression in epididymal and subcutaneous adipose tissue induced by leptin deficiency. Gene expression levels of Col6a1 and Col6a3 in EWAT (a, b) and SCWAT $(\mathbf{c}, \mathbf{d})$. The gene expression in WT mice was assumed to be 1 . Differences between groups were analyzed by two-way ANOVA

or one-way ANOVA followed by Tukey's post hoc test when an interaction between factors was detected. ${ }^{\mathrm{a}} p<0.001$, effect of the absence of $o b$ gene. $* p<0.05, * * p<0.01$ vs WT mice; ${ }^{\#} p<0.05,{ }^{\# \#} p$ $<0.01$ vs $o b / o b$ mice

0.01) in mRNA Tnc expression compared to basal or leptinstimulated adipocytes was observed in 3T3-L1 adipocytes after PI3K inhibition (Supplemental Fig. 4).

\section{Gene silencing of iNOS and pharmacological inhibition of iNOS reverted the proinflammatory effect of leptin in 3T3-L1 adipocytes}

To further confirm the contribution of iNOS in mediating leptin-induced inflammation in 3T3-L1 adipocytes, the constitutive expression levels of the $i N O S$ gene was reduced by using specific siRNA or pharmacological inhibitors of iNOS. Gene silencing of the iNOS expression resulted in the downregulation $(p<0.01)$ of Tnc mRNA under basal conditions and after leptin stimulation (Fig. 6a). Furthermore, $T n c$ was significantly $(p<0.05)$ increased after leptin treatment both in the control and the iNOS knockdown groups. Accordingly, the preincubation of 3T3-L1 adipocytes with both L-NAME or L-NIL blunted the leptin-induced increase in Tnc mRNA levels (Fig. 6b) as well as TNC release to the culture media (Fig. 6c). These results directly demonstrate the contribution of iNOS in TNC expression and secretion in differentiated 3T3-L1 adipocytes.

\section{Discussion}

Adipocytes are active players in AT inflammation due to their ability to express many proinflammatory cytokines and

to induce the activation and recruitment of immune cells ${ }^{47}$. Our results are consistent with previous studies demonstrating the role of leptin in WAT inflammation and fibro$\operatorname{sis}^{48,49}$. Inflammatory factors including TNF- $\alpha$, IL- $1 \beta$, or LPS stimulate leptin expression in fat cells ${ }^{50,51}$, and leptin in turn induces monocyte-macrophage chemotaxis and potentiates the production of the proinflammatory cytokines TNF- $\alpha$ and IL- $6^{52,53}$, perpetuating AT inflammation. We confirmed the ability of leptin to stimulate Tnf mRNA expression in murine 3T3-L1 adipocytes, but not in undifferentiated preadipocytes. Interestingly, our data revealed that leptin also promoted the synthesis and release of TNC, an endogenous activator of Toll-like receptor 4 (TLR4) that is key for the production of proinflammatory cytokines and ECM remodeling ${ }^{19,22}$. TNC expression can be induced in adipocytes after stimulation with proinflammatory cytokines and/or by growth factors from activated macrophages $^{11}$, probably via TLR $4{ }^{22}$. However, contribution of serum TNC by other peripheral organs cannot be ruled out. Hypoxia or mechanical stress, present in inflamed tissues, can also induce TNC expression, and the incubation of fibroblasts with TNC induces potent fibrotic responses ${ }^{54}$. Nevertheless, stimulation of 3T3-L1 adipocytes with TNC did not change the transcription of $T n f$ or fibrotic genes, including Col6al and Col6a3. Taken together, the secretion of the alarmin TNC by adipocytes in the context of genetic obesity seems to worsen the existing AT fibrosis by targeting stromal cells, which constitute the major source of production of ECM components ${ }^{45}$. 
Fig. 4 Effect of leptin replacement on the expression of genes involved in inflammation and fibrosis in $o b / o b$ mice. Gene expression levels of Emrl (a), Tnf (b), Hifla (c), Tnc (d), and Col6a3 (e) in wild type (WT), $o b / o b$, leptin-treated, and pairfed $o b / o b$ mice $(n=5$ per group). Gene expression levels in WT mice in white adipose tissue (WAT) were assumed to be 1. f Bar graphs show TNC serum levels. Differences between groups were analyzed by one-way ANOVA followed by Tukey's post hoc tests. *p< $0.05, * * * p<0.001$ vs WT mice; ${ }^{\#} p<0.05,{ }^{\# \#} p<0.01$ vs $o b / o b$ mice
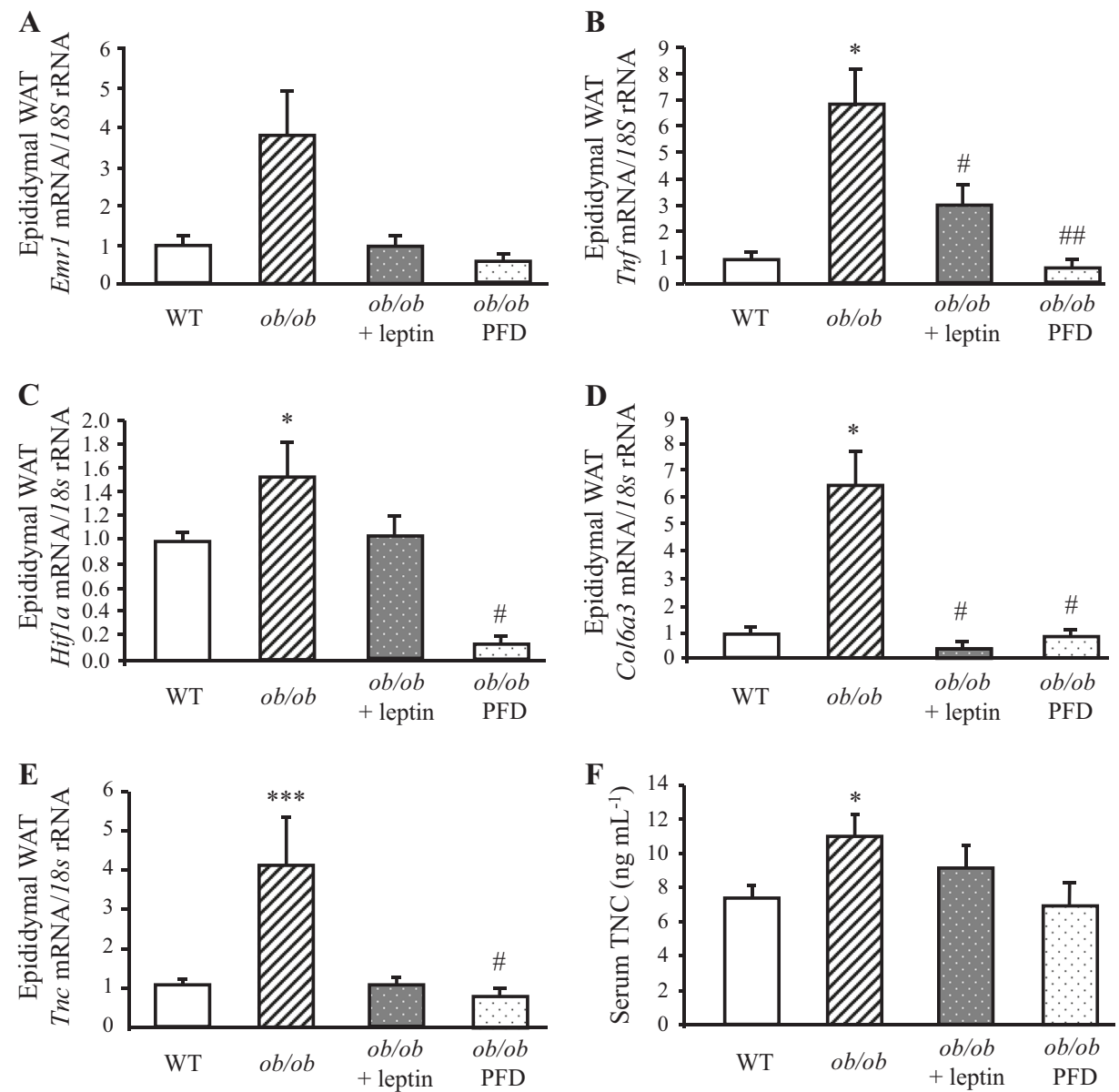

The activation of the PI3K/Akt transduction signaling is necessary for leptin-induced macrophage migration ${ }^{52}$ and proinflammatory cytokine production ${ }^{55}$ in several cell types $^{46,56}$. In this regard, we found that the covalent, irreversible inhibitor of PI3K, wortmannin ${ }^{57}$, decreased $T n c$ gene expression levels in differentiated 3T3-L1 adipocytes. Taken together, leptin acts in an autocrine/paracrine manner via the PI3K/Akt signaling pathway, contributing to sustain adipocyte inflammation through the synthesis and release of the alarmin TNC. Data are based on the immortalized cell line 3T3-L1 since the preadipose cell line 3T3-L1 is one of the most common in vitro models used in the study of adipocyte biology due to its potential to differentiate from fibroblasts to adipocytes ${ }^{58}$. However, 3T3-L1 adipocytes display features of multiple adipocyte lineages, and this should be taken into consideration when interpreting data from experiments using this cell line ${ }^{59}$.

Leptin influences energy homeostasis and immune system, constituting a cornerstone of the new field of immunometabolism ${ }^{24}$. Leptin-deficient $o b / o b$ mice exhibited an increased AT inflammation and fibrosis, evidenced by higher AT macrophage infiltration and collagen deposition. Hypoxia constitutes an essential factor contributing to AT inflammation and fibrosis ${ }^{17}$. HIF-1 $\alpha$ induction by AT hypoxia triggers the upregulation of genes involved in the fibrotic response, resulting in the excess deposition of ECM components, which may cause adipocyte death and inflammation, being also strongly associated with systemic insulin resistance $e^{60,61}$. In line with this observation, our data showed that genes involved in the regulation of hypoxic response (Hifla), inflammation (Tnf, Emrl), and excessive collagen deposition (Col6al and Col6a3) were highly enriched in EWAT of leptin-deficient $o b / o b$ mice. Moreover, circulating levels and EWAT expression of the alarmin TNC were also significantly increased in $o b / o b$ mice, contributing to the sustained inflammatory response and ECM remodeling associated to obesity ${ }^{22}$. Our results provide further evidence that in vivo chronic leptin administration reverted obesity, metabolic disturbances, as well as reduced the expression of hypoxic, proinflammatory and profibrotic genes. However, these phenomena cannot exclusively be conducted by leptin, since similar results were obtained in the pair-fed group, suggesting that other factors might be operative in the beneficial effect in the inflammatory response independently of weight $\operatorname{loss}^{33,62}$. 
Fig. 5 Effect of leptin and tenascin $\mathrm{C}$ treatment on the expression of markers of inflammation and fibrosis in 3T3-L1 adipocytes. Effect of leptin stimulation $\left(10 \mathrm{nmol} \mathrm{L}^{-1}\right)$ for $24 \mathrm{~h}$ on gene expression levels of Tnf (a), Hifla (b), Col6a3 (c), and Tnc (d) as well as on TNC release to the culture media (e) in differentiated 3T3L1 adipocytes ( $n=5$ per group). Effect of stimulation with tenascin $\mathrm{C}$ (TNC) $\left(10 \mathrm{nmol} \mathrm{L}^{-1}\right)$ for $24 \mathrm{~h}$ on gene expression levels of $\operatorname{Tnf}(\mathbf{f})$, Col6al (g), and Col6a3 (h) in differentiated 3T3-L1 adipocytes $(n=5$ per group). Differences between groups were analyzed by unpaired two-tailed Student's $t$-tests. $* p<0.05$ vs unstimulated cells
A

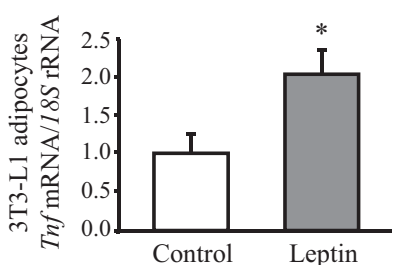

D

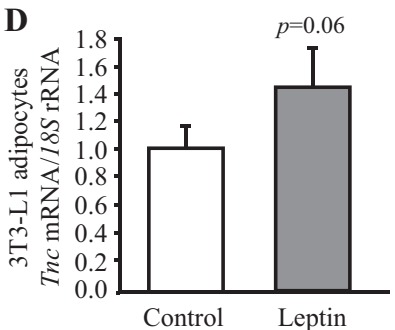

F

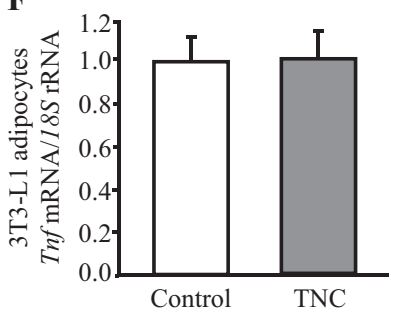

B
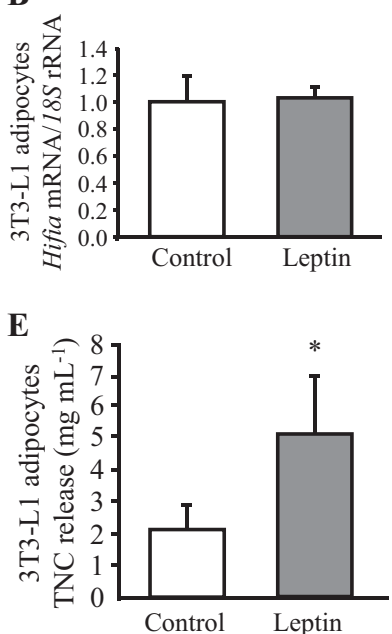

G

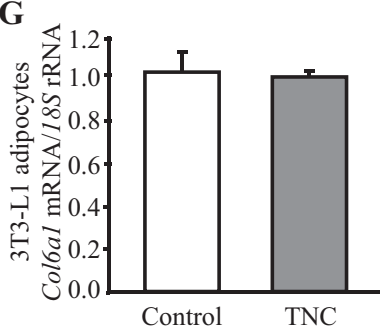

$\mathrm{C}$

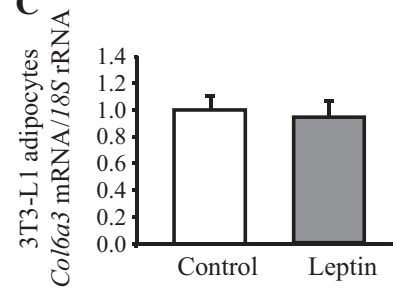

H

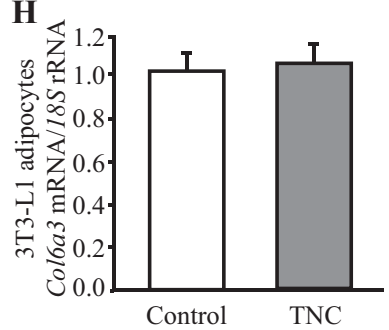

Previous studies showed that $\mathrm{NOS}^{-/-}$mice are protected from HFD-induced AT inflammation and fibrosis ${ }^{63}$. In this sense, NO produced by active macrophages promotes a profibrogenic response via the activation of HIF- $1 \alpha$ in preadipocytes that results in local adipocytes fibrosis and necrosis, M1 macrophage polarization, and systemic insulin resistance ${ }^{63}$. Accordingly, we provide evidence, for the first time, that iNOS plays a major role in AT inflammation and fibrosis associated with congenital leptin deficiency. Several plausible mechanisms can explain the improvement of AT fibrosis and metabolic dysfunction in the DBKO mice. Firstly, iNOS deficiency in $o b / o b$ mice reduces adipocyte enlargement, which positively correlates with insulin resistance ${ }^{64}$. These observations are in line with the present work showing the limitation in the accumulation of lipids in adipocytes together with the increased levels of adiponectin and the reduced AT inflammatory profile in DBKO mice could be related with the improved insulin sensitivity. Secondly, contrary to the results obtained by Jang et al. ${ }^{63}$, our findings revealed that EWAT from $i N O S^{-1-}$ and DBKO mice presented a dramatic reduction in Hifla, a major contributor of AT inflammation and fibrosis. Interestingly, HIF- $1 \alpha$ is a positive regulator of iNOS and, conversely, NO produced by iNOS increases HIF-1 $\alpha$ stability ${ }^{65,66}$. Thus, iNOS disruption might ameliorate AT hypoxia in $o b / o b$ mice by decreasing the transcription and stability of HIF- $1 \alpha$.
Accordingly, the lower transcript levels of the proangiogenic and hypoxia-sensitive Vegfa gene in iNOS-deficient mice might reflect a lesser need of capillary network expansion due to the improved AT hypoxia. Thirdly, we found that $i \mathrm{NOS}^{-1-}$ and DBKO mice exhibited a profound decrease in collagen deposition in Sirius red-stained sections of AT together with a downregulation of Col6al and Col6a3, the genes encoding collagen VI, the major component of ECM in rodents. In this sense, the deletion of Col6a3 leads to the improvement in metabolic health in obese, diabetic $o b / o b$ mice ${ }^{67}$, which is in accordance with the improved obese and diabetic phenotype of our DBKO model reported by our group and others ${ }^{26,68}$. Finally, our results showed that $i N O S$ deletion in $o b / o b$ mice significantly reduces circulating levels and AT expression of the alarmin TNC. Similarly, iNOS gene silencing and pharmacological inhibition of iNOS induced a downregulation of leptin-induced Tnc transcript levels. These finding suggests that leptin activates TNC via a NOdependent mechanism. Although obesity affects both males and females, a sexual dimorphism exists in the development of obesity-associated metabolic complications ${ }^{69}$. Thus, further studies are warranted to analyze the impact of iNOS disruption in the sexual dimorphism of obesity.

The impact of $i N O S$ deletion on AT function in the context of leptin deficiency was addressed analyzing 

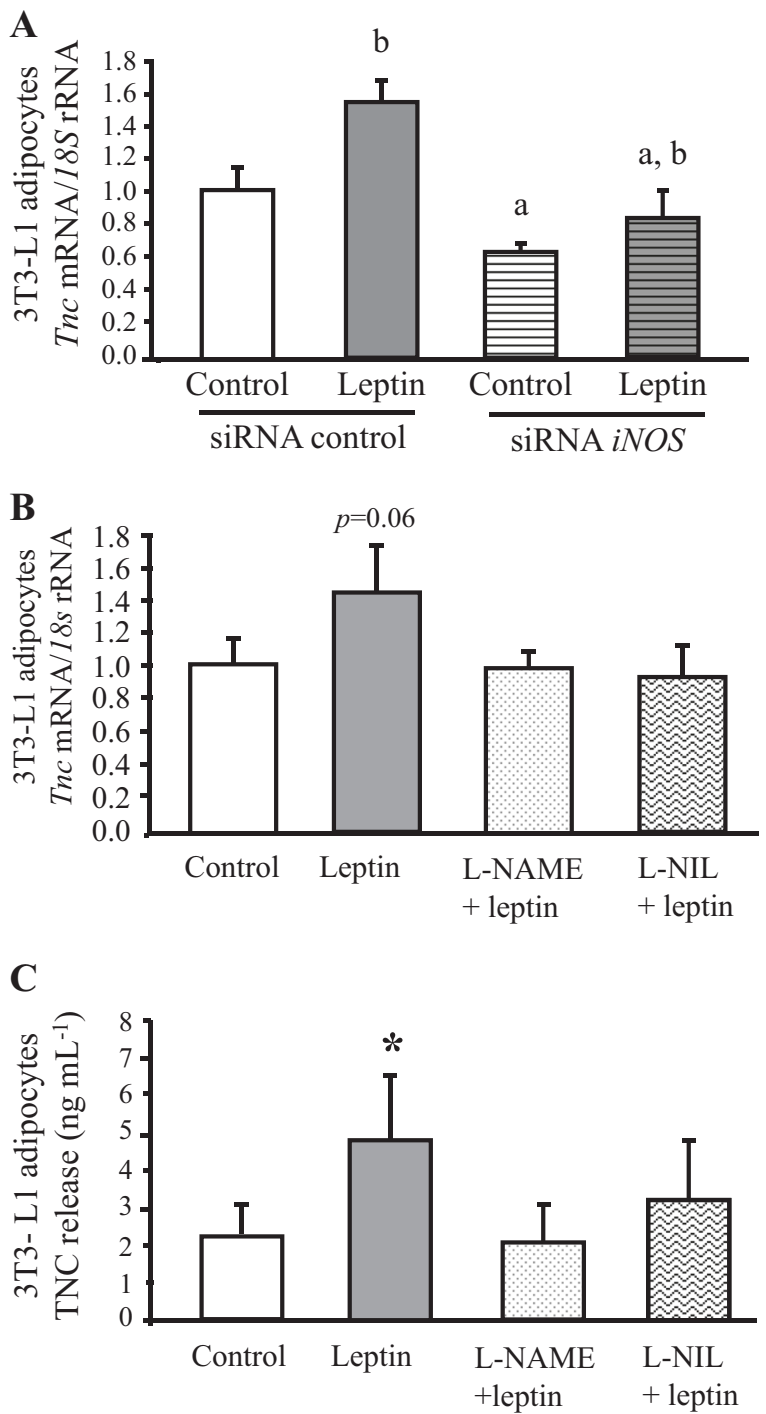

Fig. 6 Effect of gene silencing of $i N O S$ and pharmacological inhibition of iNOS on the expression of Tnc in leptin-treated 3T3-L1 adipocytes. a mRNA expression levels of Tnc in scrambled siRNA control and iNOS knockdown 3T3-L1 adipocytes under basal conditions and after leptin $\left(10 \mathrm{nmol} \mathrm{L}^{-1}\right)$ stimulation for $24 \mathrm{~h}$ ( $n=6$ per group). Gene expression levels in scrambled siRNA control cells were assumed to be 1. Bar graphs show transcript levels of $T n c$ (b) and TNC release to the culture media $(\mathbf{c})$ in leptin $\left(10 \mathrm{nmol} \mathrm{L}^{-1}\right)$-stimulated 3T3-L1 adipocytes in the presence or absence of L-NAME $\left(10 \mu \mathrm{mol} \mathrm{L}^{-1}\right)$ or L-NIL $\left(10 \mu \mathrm{mol} \mathrm{L}^{-1}\right)$ inhibitors for $24 \mathrm{~h}$ ( $n=6$ per group). Differences between groups were analyzed by two-way ANOVA or one-way ANOVA followed by Tukey's post hoc tests. ${ }^{\mathrm{a}} p<0.05$, effect of leptin; ${ }^{\mathrm{b}} p<0.05$, effect of the absence of the $i N O S$ gene. $* p<0.05$ vs unstimulated cells

markers of adipogenesis (Pparg, Fasn, and Cidec) and fat browning (Prdm16 and Ucpl). It was shown that ob/ob mice exhibited larger adipocytes with the absence of the $i N O S$ gene in $o b / o b$ mice significantly decreasing adipocyte size in epididymal AT. Furthermore, a tendency towards an increase in the transcript levels of the master transcription factor of adipogenesis PPAR $\gamma$ as well as an upregulation of
Fasn was observed in epididymal AT of $o b / o b$ mice. The deletion of iNOS significantly decreased Fasn mRNA levels, but not Pparg transcripts ${ }^{70}$. In a prior work, we found that leptin constitutes a positive regulator of fat browning process through the upregulation of Prdm16, Ucp1, and Cidec in murine subcutaneous adipocytes ${ }^{71}$. Accordingly, leptin deficiency was associated with a downregulation of Prdm16, a zinc-finger protein involved in the expression of brown fat-selective genes, and $U c p l$, a brown- and beige-specific marker, together with an upregulation of Cidec, which promotes lipid droplet formation in subcutaneous $\mathrm{AT}^{72}$, suggesting an impaired fat browning in the context of leptin deficiency. Interestingly, the deletion of iNOS upregulated Prdm16 mRNA levels and tended to increase Ucpl transcript levels. Taken together, iNOS deletion improved AT function in $o b / o b$ mice through the reduction of adipocyte hypertrophy in epididymal AT and the improvement of fat browning-selective gene expression in subcutaneous AT.

In summary, leptin is able to downregulate ECM components in an obesogenic environment via NO-dependent mechanisms. We herein demonstrate that deletion of the iNOS gene in $o b / o b$ mice reverses AT inflammation and fibrosis, contributing to the improvement of metabolic function. NO produced by adipocytes is necessary for the synthesis and release of profibrogenic and proinflammatory $\mathrm{TNC}$, suggesting a crucial role of this alarmin in the development of AT fibrosis in the obese state. Further research is needed to disentangle the specific function of leptin and iNOS in ECM remodeling.

Acknowledgements We gratefully acknowledge the valuable collaboration of all the staff of the breeding house of the University of Navarra. This work was supported by the Instituto de Salud Carlos III and fondos FEDER (PI16/00221 and PI16/01217) and by the Department of Health of Gobierno de Navarra (61/2014). CIBER de Fisiopatología de la Obesidad y Nutrición (CIBEROBN) is an initiative of the Instituto de Salud Carlos III, Spain.

\section{Compliance with ethical standards}

Conflict of interest The authors declare that they have no conflict of interest.

Open Access This article is licensed under a Creative Commons Attribution 4.0 International License, which permits use, sharing, adaptation, distribution and reproduction in any medium or format, as long as you give appropriate credit to the original author(s) and the source, provide a link to the Creative Commons license, and indicate if changes were made. The images or other third party material in this article are included in the article's Creative Commons license, unless indicated otherwise in a credit line to the material. If material is not included in the article's Creative Commons license and your intended use is not permitted by statutory regulation or exceeds the permitted use, you will need to obtain permission directly from the copyright holder. To view a copy of this license, visit http://creativecommons. org/licenses/by/4.0/. 


\section{References}

1. Lawler HM. et al. Adipose tissue hypoxia, inflammation, and fibrosis in obese insulin-sensitive and obese insulin-resistant subjects. J Clin Endocrinol Metab. 2016;101:1422-8.

2. Frühbeck G, Gómez-Ambrosi J. Rationale for the existence of additional adipostatic hormones. FASEB J. 2001;15:1996-2006.

3. Weisberg SP. et al. Obesity is associated with macrophage accumulation in adipose tissue. J Clin Invest. 2003;112:1796-808.

4. Hotamisligil GS, Shargill NS, Spiegelman BM. Adipose expression of tumor necrosis factor-a: direct role in obesity-linked insulin resistance. Science. 1993;259:87-91.

5. Lumeng CN, Bodzin JL, Saltiel AR. Obesity induces a phenotypic switch in adipose tissue macrophage polarization. J Clin Invest. 2007; 117:175-84.

6. Divoux A, Clement K. Architecture and the extracellular matrix: the still unappreciated components of the adipose tissue. Obes Rev. 2011;12:e494-e503.

7. Shaul ME, Bennett G, Strissel KJ, Greenberg AS, Obin MS. Dynamic, M2-like remodeling phenotypes of CD11c+ adipose tissue macrophages during high-fat diet--induced obesity in mice. Diabetes. 2010;59:1171-81.

8. Sun L. et al. Mir193b-365 is essential for brown fat differentiation. Nat Cell Biol. 2011;13:958-65.

9. Calay ES, Hotamisligil GS. Turning off the inflammatory, but not the metabolic, flames. Nat. Med. 2013;19:265-7.

10. Kratz M. et al. Metabolic dysfunction drives a mechanistically distinct proinflammatory phenotype in adipose tissue macrophages. Cell Metab. 2014;20:614-25.

11. Keophiphath M. et al. Macrophage-secreted factors promote a profibrotic phenotype in human preadipocytes. Mol Endocrinol. 2009;23:11-24.

12. Furukawa $\mathrm{S}$. et al. Increased oxidative stress in obesity and its impact on metabolic syndrome. J Clin Invest. 2004;114:1752-61.

13. Kaneki M, Shimizu N, Yamada D, Chang K. Nitrosative stress and pathogenesis of insulin resistance. Antioxid Redox Signal. 2007;9:319-29.

14. Kloting N, Bluher M. Adipocyte dysfunction, inflammation and metabolic syndrome. Rev Endocr Metab Disord. 2014;15:277-87.

15. Sun K, Tordjman J, Clement K, Scherer PE. Fibrosis and adipose tissue dysfunction. Cell Metab. 2013;18:470-7.

16. Guglielmi V. et al. Omental adipose tissue fibrosis and insulin resistance in severe obesity. Nutr Diabetes. 2015;5:e175.

17. Hallberg M, et al. A functional interaction between RIP140 and PGC-1a regulates the expression of the lipid droplet protein CIDEA. Mol Cell Biol. 2008;28:6785-95.

18. Midwood KS, Hussenet T, Langlois B, Orend G. Advances in tenascin-C biology. Cell Mol Life Sci. 2011;68:3175-99.

19. Midwood K. et al. Tenascin-C is an endogenous activator of Tolllike receptor 4 that is essential for maintaining inflammation in arthritic joint disease. Nat Med. 2009;15:774-80.

20. Carey WA, Taylor GD, Dean WB, Bristow JD. Tenascin-C deficiency attenuates TGF-ss-mediated fibrosis following murine lung injury. Am J Physiol Lung Cell Mol Physiol. 2010;299: L785-93.

21. El-Karef A. et al. Deficiency of tenascin-C attenuates liver fibrosis in immune-mediated chronic hepatitis in mice. J Pathol. 2007;211:86-94.

22. Catalán V. et al. Increased tenascin C and Toll-like receptor 4 levels in visceral adipose tissue as a link between inflammation and extracellular matrix remodeling in obesity. J Clin Endocrinol Metab. 2012;97:E1880-9.

23. Zhang Y. et al. Positional cloning of the mouse obese gene and its human homologue. Nature. 1994;372:425-32.
24. Pérez-Pérez A. et al. Role of leptin as a link between metabolism and the immune system. Cytokine Growth Factor Rev. 2017;35:71-84.

25. La Cava A, Matarese G. The weight of leptin in immunity. Nat Rev Immunol. 2004;4:371-9.

26. Becerril S. et al. Deletion of inducible nitric-oxide synthase in leptin-deficient mice improves brown adipose tissue function. PLoS ONE. 2010;5:e10962.

27. Frühbeck G. Pivotal role of nitric oxide in the control of blood pressure after leptin administration. Diabetes. 1999;48:903-8.

28. Frühbeck G, Gómez-Ambrosi J. Modulation of the leptin-induced white adipose tissue lipolysis by nitric oxide. Cell Signal. 2001;13:827-33.

29. Rodríguez A. et al. The inhibitory effect of leptin on angiotensin II-induced vasoconstriction in vascular smooth muscle cells is mediated via a nitric oxide-dependent mechanism. Endocrinology. 2007;148:324-31.

30. Shiuchi T. et al. Involvement of bradykinin and nitric oxide in leptin-mediated glucose uptake in skeletal muscle. Endocrinology. 2001;142:608-12.

31. Dixit VD, Mielenz M, Taub DD, Parvizi N. Leptin induces growth hormone secretion from peripheral blood mononuclear cells via a protein kinase C- and nitric oxide-dependent mechanism. Endocrinology. 2003;144:5595-603.

32. Becerril S. et al. Transcriptional analysis of brown adipose tissue in leptin-deficient mice lacking inducible nitric oxide synthase: evidence of the role of Med1 in energy balance. Physiol Genom. 2012;44:678-88.

33. Sáinz $\mathrm{N}$, et al. Leptin administration favors muscle mass accretion by decreasing FoxO3a and increasing PGC-1a in $o b / o b$ mice. PLoS ONE. 2009;4:e6808.

34. Muruzábal FJ, Frühbeck G, Gómez-Ambrosi J, Archanco M, Burrell MA. Immunocytochemical detection of leptin in nonmammalian vertebrate stomach. Gen Comp Endocrinol. 2002;128:149-52.

35. Sáinz N. et al. Leptin administration downregulates the increased expression levels of genes related to oxidative stress and inflammation in the skeletal muscle of ob/ob mice. Mediat Inflamm. 2010;2010:784343.

36. Catalán V. et al. Expression of caveolin-1 in human adipose tissue is upregulated in obesity and obesity-associated type 2 diabetes mellitus and related to inflammation. Clin Endocrinol. 2008;68:213-9.

37. Catalán V. et al. Validation of endogenous control genes in human adipose tissue: relevance to obesity and obesity-associated type 2 diabetes mellitus. Horm Metab Res. 2007;39:495-500.

38. Halberg N, et al. Hypoxia-inducible factor 1a induces fibrosis and insulin resistance in white adipose tissue. Mol Cell Biol. 2009;29:4467-83.

39. Rodríguez A. et al. Insulin- and leptin-mediated control of aquaglyceroporins in human adipocytes and hepatocytes is mediated via the PI3K/Akt/mTOR signaling cascade. J Clin Endocrinol Metab. 2011;96:E586-97.

40. Kanuri BN. et al. Altered glucose and lipid homeostasis in liver and adipose tissue pre-dispose inducible NOS knockout mice to insulin resistance. Sci Rep. 2017;7:41009.

41. Perreault M, Marette A. Targeted disruption of inducible nitric oxide synthase protects against obesity-linked insulin resistance in muscle. Nat Med. 2001;7:1138-43.

42. Fujimoto M. et al. A role for iNOS in fasting hyperglycemia and impaired insulin signaling in the liver of obese diabetic mice. Diabetes. 2005;54:1340-8.

43. Voros G. et al. Modulation of angiogenesis during adipose tissue development in murine models of obesity. Endocrinology. 2005;146:4545-54. 
44. Gómez-Ambrosi J. et al. Involvement of serum vascular endothelial growth factor family members in the development of obesity in mice and humans. J Nutr Biochem. 2010;21: 774-80.

45. Divoux A. et al. Fibrosis in human adipose tissue: composition, distribution, and link with lipid metabolism and fat mass loss. Diabetes. 2010;59:2817-25.

46. Fruhbeck G. Intracellular signalling pathways activated by leptin. Biochem J. 2006;393:7-20.

47. Meijer K. et al. Human primary adipocytes exhibit immune cell function: adipocytes prime inflammation independent of macrophages. PLoS ONE. 2011;6:e17154

48. Buechler C, Krautbauer S, Eisinger K. Adipose tissue fibrosis. World J Diabetes. 2015;6:548-53.

49. Loffreda $S$. et al. Leptin regulates proinflammatory immune responses. Faseb J. 1998;12:57-65.

50. Kirchgessner TG, Uysal KT, Wiesbrock SM, Marino MW, Hotamisligil GS. Tumor necrosis factor-a contributes to obesityrelated hyperleptinemia by regulating leptin release from adipocytes. J Clin Invest. 1997;100:2777-82.

51. Grunfeld C. et al. Endotoxin and cytokines induce expression of leptin, the $\mathrm{o} b$ gene product, in hamsters. J Clin Invest. 1996;97:2152-7.

52. Gruen ML, Hao M, Piston DW, Hasty AH. Leptin requires canonical migratory signaling pathways for induction of monocyte and macrophage chemotaxis. Am J Physiol Cell Physiol. 2007;293:C1481-8.

53. Lee SM, Choi HJ, Oh CH, Oh JW, Han JS. Leptin increases TNFa expression and production through phospholipase D1 in Raw 264.7 cells. PLoS ONE. 2014;9:e102373.

54. Bhattacharyya S. et al. Tenascin-C drives persistence of organ fibrosis. Nat Commun. 2016;7:11703

55. Shen Y, Wang Q, Zhao Q, Zhou J. Leptin promotes the immune escape of lung cancer by inducing proinflammatory cytokines and resistance to apoptosis. Mol Med Rep. 2009;2:295-9.

56. Hirsch E, Costa C, Ciraolo E. Phosphoinositide 3-kinases as a common platform for multi-hormone signaling. J Endocrinol. 2007;194:243-56.

57. Powis G. et al. Wortmannin, a potent and selective inhibitor of phosphatidylinositol-3-kinase. Cancer Res. 1994;54:2419-23.
58. Poulos SP, Dodson MV, Hausman GJ. Cell line models for differentiation: preadipocytes and adipocytes. Exp Biol Med (Maywood). 2010;235:1185-93.

59. Morrison S, McGee SL. 3T3-L1 adipocytes display phenotypic characteristics of multiple adipocyte lineages. Adipocyte. 2015;4:295-302.

60. Williams AS, Kang L, Wasserman DH. The extracellular matrix and insulin resistance. Trends Endocrinol Metab. 2015;26:357-66.

61. Olefsky JM, Glass CK. Macrophages, inflammation, and insulin resistance. Annu Rev Physiol. 2010;72:219-46.

62. Cousin B. et al. Cellular changes during cold acclimatation in adipose tissues. J Cell Physiol. 1996;167:285-9.

63. Jang JE. et al. Nitric oxide produced by macrophages inhibits adipocyte differentiation and promotes profibrogenic responses in preadipocytes to induce adipose tissue fibrosis. Diabetes. 2016;65:2516-28.

64. Weyer C, Foley JE, Bogardus C, Tataranni PA, Pratley RE. Enlarged subcutaneous abdominal adipocyte size, but not obesity itself, predicts type II diabetes independent of insulin resistance. Diabetologia. 2000;43:1498-506.

65. Kleinert H, Pautz A, Linker K, Schwarz PM. Regulation of the expression of inducible nitric oxide synthase. Eur J Pharmacol. 2004;500:255-66.

66. Brune B, Zhou J. Hypoxia-inducible factor-1a under the control of nitric oxide. Methods Enzymol. 2007;435:463-78.

67. Khan T. et al. Metabolic dysregulation and adipose tissue fibrosis: role of collagen VI. Mol Cell Biol. 2009;29:1575-91.

68. Sugita $\mathrm{H}$. et al. Inducible nitric-oxide synthase and NO donor induce insulin receptor substrate-1 degradation in skeletal muscle cells. J Biol Chem. 2005;280:14203-11.

69. Palmer BF, Clegg DJ. The sexual dimorphism of obesity. Mol Cell Endocrinol. 2015;402:113-9.

70. Ortega FJ. et al. The gene expression of the main lipogenic enzymes is downregulated in visceral adipose tissue of obese subjects. Obesity. 2010;18:13-20.

71. Rodríguez A. et al. Leptin administration activates irisin-induced myogenesis via nitric oxide-dependent mechanisms, but reduces its effect on subcutaneous fat browning in mice. Int $\mathrm{J}$ Obes. 2015;39:397-407.

72. Sun Z. et al. Perilipin1 promotes unilocular lipid droplet formation through the activation of Fsp27 in adipocytes. Nat Commun. 2013;4:1594 